RESEARCH PAPER RP928

Part of Journal of Research of the National Bureau of Standards, Volume 17, October 1936

\title{
OXIDATION OF WOOL: ALKALI-SOLUBILITY TEST FOR DETERMINING THE EXTENT OF OXIDATION ${ }^{1}$
}

\author{
By Milton Harris and Arthur L. Smith ${ }^{2}$
}

\section{ABSTRACT}

Oxidizing agents attack the disulfide groups of the cystine in wool and increase the solubility of the wool in alkaline solutions. The determination of the alkalisolubility may be used as a measure of the extent to which the wool is oxidized. The method is applicable as a control in practical processes, such as bleaching and chlorination, and offers a measure of the extent to which wool is degraded by photochemical reactions. Data are presented which indicate a relationship between the chemical and physical degradation of wool fibers.

I. Introduction

CONTENTS

II. Methods $\ldots \ldots \ldots$

III. Application of the alkali-solubility test_.

1. Hydrogen peroxide bleaching 578

2. Chlorination and bromination $\ldots \ldots \ldots$

3. Effect of light on wool 581

IV. Conclusions _............

V. References

\section{INTRODUCTION}

In practical processing, wool is often exposed to conditions in which it may become partially oxidized. Under extreme conditions, such as may be encountered during severe bleaching or chlorination, the wool is oxidized to such an extent that the damage is readily detectable by visual examination or by ordinary physical testing methods. In well-controlled processes, however, the amount of oxidation is barely or not at all measurable by ordinary testing methods. The incipient damage which may be produced by mild oxidation is usually developed and accentuated during subsequent processing. It is apparent, therefore, that analytical methods for determining the extent of oxidation of wool are of importance for effective control during its processing.

In a series of studies relating to the oxidation of wool and to the effect of alkalies on untreated and on oxidized wool $[1,2,3,4],{ }^{3}$ it was shown that the main point of attack by both oxidizing and alkaline reagents was the disulfide group of the cystine in wool. It was also

\footnotetext{
1 This is the fourth paper of a series of studies relating to the oxidation of wool.

2 Research associates at the National Bureau of Standards, representing the American Association of Textile Chemists and Colorists.

3 The numbers in brackets here and elsewhere in the text relate to the numbered references at the end of this paper.
} 
shown that the oxidized wool is more susceptible to alkaline treatment than untreated wool, and that the extent to which the wool is oxidized bears a functional relationship to the decrease in the cystine content and to the increase in the alkali-solubility. Although determinations of either the cystine content or the alkali-solubility are measures of the extent of oxidation of wool, the former is not practical since it requires equipment, technique, and time which are not ordinarily available in the average textile-mill laboratory. On the other hand, the latter method is comparatively rapid and simple, and, in most instances, appears to be more sensitive.

The present paper deals with the application of the alkali-solubility test to a number of practical processes in which wool is subjected to oxidation reactions. Comparative data obtained from corresponding cystine analyses are also presented.

\section{METHODS}

Alkali-solubility was determined by treating the wool with a $0.1 \mathrm{~N}$ solution of sodium hydroxide at $65^{\circ} \mathrm{C}$ for 1 hour, the ratio of wool to solution being approximately $1: 100$, by weight. The wool was recovered on a Büchner funnel, washed with about 2 liters of water, dried to constant weight at $105^{\circ} \mathrm{C}$, and the loss in weight determined. Samples of wool which had been severely oxidized became gelatinous during the alkali treatment. These samples were partially dried in an oven at about $50^{\circ} \mathrm{C}$ for 1 hour and then dried at $105^{\circ} \mathrm{C}$. The cystine content was determined by the Sullivan method [5]. Data showing the reproducibilities which may be expected by both methods are given in table 1 .

TABLE 1.-Results of six analyses of untreated wool yarn to show reproducibility

The values are based on the oven-dry weight of the wool.

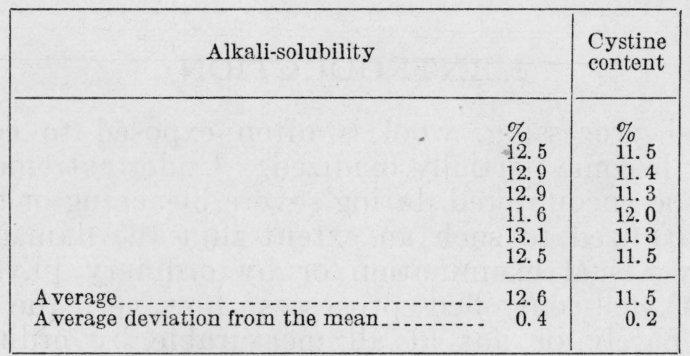

\section{APPLICATIONS OF THE ALKALI-SOLUBILITY TEST}

\section{HYDROGEN PEROXIDE BLEACHING}

In a previous paper [2] on the effect of hydrogen peroxide on wool, data were presented showing the effects of varying the concentration, temperature, and $\mathrm{pH}$ of the hydrogen peroxide solutions and the duration of the treatment. Data taken from that paper on the effect of varying the temperature of the bleach bath are presented in table 2 as a typical example of the use of the alkali-solubility test for studying and controlling the bleaching process. 
TABLE 2.-Effect on wool of 2-volume $(0.6 \%)$ solutions of hydrogen peroxide at various temperatures from 23 to $80^{\circ} \mathrm{C}$, for 3 hours; and the alkali-solubility of the treated wool

\begin{tabular}{|c|c|c|}
\hline $\begin{array}{c}\text { Tempera- } \\
\text { ture of } \\
\mathrm{H}_{2} \mathrm{O}_{2} \text { solu- } \\
\text { tion }\end{array}$ & $\begin{array}{c}\text { Alkali- } \\
\text { solubility }\end{array}$ & $\begin{array}{c}\text { Cystine } \\
\text { content } \\
\text { after treat- } \\
\text { ment with } \\
\mathrm{H}_{2} \mathrm{O}_{2}\end{array}$ \\
\hline & & \\
\hline${ }^{\circ} \mathrm{C}$ & $\%$ & $\%$ \\
23 & 9.7 & 11.2 \\
35 & 13.6 & 11.3 \\
50 & 19.4 & 10.8 \\
65 & 31.6 & 9.8 \\
80 & 100.0 & 7.4 \\
\hline
\end{tabular}

The use of the method as a control for commercial bleaching operations was also investigated. The effects of successive commercial bleaching treatments on wool cloth are recorded in table 3 . The values for the swelling, shown in the last column of table 3, were obtained by Von Bergen's method [5]. ${ }^{4}$ The results obtained by all of the methods are in good agreement, but the swelling method, like that for cystine, requires technique and equipment which are not usually available.

\section{TABLE 3.-Effect of commercial bleaching on the alkali-solubility, cystine content, and} swelling in alkali of wool cloth

The wool was bleached in hydrogen peroxide at $\mathrm{pH} 9.8$ and at a temperature of $120^{\circ} \mathrm{F}$. The concentration of the hydrogen peroxide and the duration of the treatment are indicated in the table. After each bleaching treatment, the wool was washed, immersed for 20 minutes in a bath containing 1.2 percent of sulphuric acid and 0.25 percent of sulphur dioxide, and washed in running water for 15 minutes]

\begin{tabular}{|c|c|c|c|c|}
\hline Sample & Treatment & $\begin{array}{l}\text { Alkali- } \\
\text { solubil- } \\
\text { ity }\end{array}$ & $\begin{array}{l}\text { Cystine } \\
\text { content }\end{array}$ & Swelling \\
\hline 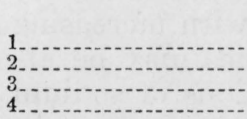 & $\begin{array}{l}\text { None } \\
\text { Bleached with } 2.71 \text {-vol. } \mathrm{H}_{2} \mathrm{O}_{2} \text { for } 113 \mathrm{hr} \\
\text { Sample } 2 \text { bleached with } 2.62 \text {-vol. } \mathrm{H}_{2} \mathrm{O}_{2} \text { for } 11 / 2 \mathrm{hr} \\
\text { Sample } 3 \text { bleached with } 1.70 \text {-vol. } \mathrm{H}_{2} \mathrm{O}_{2} \text { for } 1 \mathrm{hr} . .\end{array}$ & $\begin{array}{r}\text { Percent } \\
11.1 \\
17.2 \\
20.3 \\
31.4\end{array}$ & $\begin{array}{r}\text { Percent } \\
12.8 \\
11.7 \\
11.3 \\
10.8\end{array}$ & $\begin{array}{r}\text { Percent } \\
12.4 \\
14.7 \\
18.6 \\
21.2\end{array}$ \\
\hline
\end{tabular}

The values obtained for the alkali-solubility of a given wool sample will vary not only with the extent of oxidation but also with the construction of the material being tested; that is, the amount of surface exposed. For example, a given sample of wool will lose more weight when it is in the form of yarn than when it is in the form of a closely woven fabric. Consequently, in using the alkali-solubility test as a control in practical bleaching, the tolerances chosen will depend on the type of material being processed as well as on the uses to which it will ultimately be subjected.

\section{CHLORINATION AND BROMINATION}

The use of chlorine and bromine for the production of unshrinkable wool textiles has recently received much attention. In addition, the chlorination process is frequently used to improve the luster of wool. The great affinity of wool for these halogens and the ease with which

${ }^{4}$ These determinations were made by Dr. Von Bergen, chief chemist, Forstmann Woolen Co., Passaic, N. J. 
the fiber is damaged by them are the chief reasons for their limited use. The evaluation and minimizing of the damage are two of the important problems connected with the successful use of the processes. Since the degradation of wool by halogens appears to be brought about by oxidation reactions, the alkali-solubility test was used to study the effects of the chlorination and bromination processes.

Samples of wool yarn, each weighing approximately $4 \mathrm{~g}$, were treated for 20 minutes at room temperature with 160 -milliliter portions of sodium hypochlorite and hypochlorous acid solutions, varying in concentration from 1 to 8 percent of chlorine based on the weight of wool. The effects of the treatments are recorded in table 4.

TABLE 4.-Effect on wool yarn of sodium hypochlorite and hypochlorous acid solutions of various concentrations at room temperature for 20 minutes

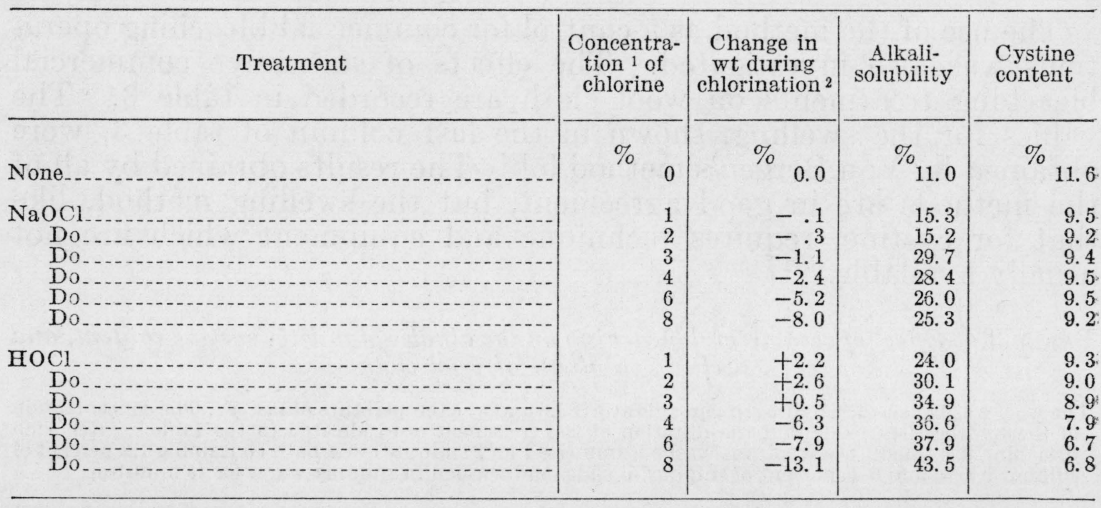

${ }_{1}$ Based on the weight of wool. $\quad{ }^{2}$ Plus sign indicates gain in weight; minus sign, loss in weight.

With the exception of those samples treated with sodium hypochlorite solutions of concentrations higher than 4 percent, the alkalisolubility increased and the cystine content decreased with increasing concentrations of chlorine. The apparent discrepancies may be attributed to the fact that the more concentrated solutions of sodium hypochlorite probably dissolve a portion of the wool that would ordinarily be removed by the subsequent alkali treatment.

It has long been known that the chlorination process tends to reduce the wearing qualities of woolen fabrics. Various investigators have attempted to estimate wearing quality of chlorinated wool by relating it to tensile strength, extensibility, the presence or absence of scales, the solubility of the wool in acids and alkalies, and the altered affinity of the wool for dyestuffs. While chlorination undoubtedly influences these properties, a definite relationship between them and wearing qualities has not previously been demonstrated.

From the standpoint of physical stability, the disulfide group constitutes what is probably the most important connecting link in the wool molecule. Since it has been shown that chloride attacks the disulfide group and increases the solubility of wool in alkalies, it seemed desirable to relate results of the alkali-solubility test to those obtained from actual wear tests.

Samples of carpet wools ${ }^{5}$ which had been treated with various con-

${ }_{5}$ The wool used for these experiments and the wear tests on the carpets were furnished by G. E. Hopkins, technical director of the Bigelow-Sanford Carpet Co., Inc., Thompsonville, Conn. 
centrations of sodium hypochlorite solutions for the purpose of producing a desired luster were analyzed for alkali-solubility and for cystine content. Wear tests on similarly treated carpets were made on a carpet wear-testing machine [6]. The numerical data are given in table 5 and shown graphically in figure 1. The results not only demonstrate further applications of the alkali-solubility test, but also indicate a definite relationship between the physical and chemical degradation of the wool fiber.

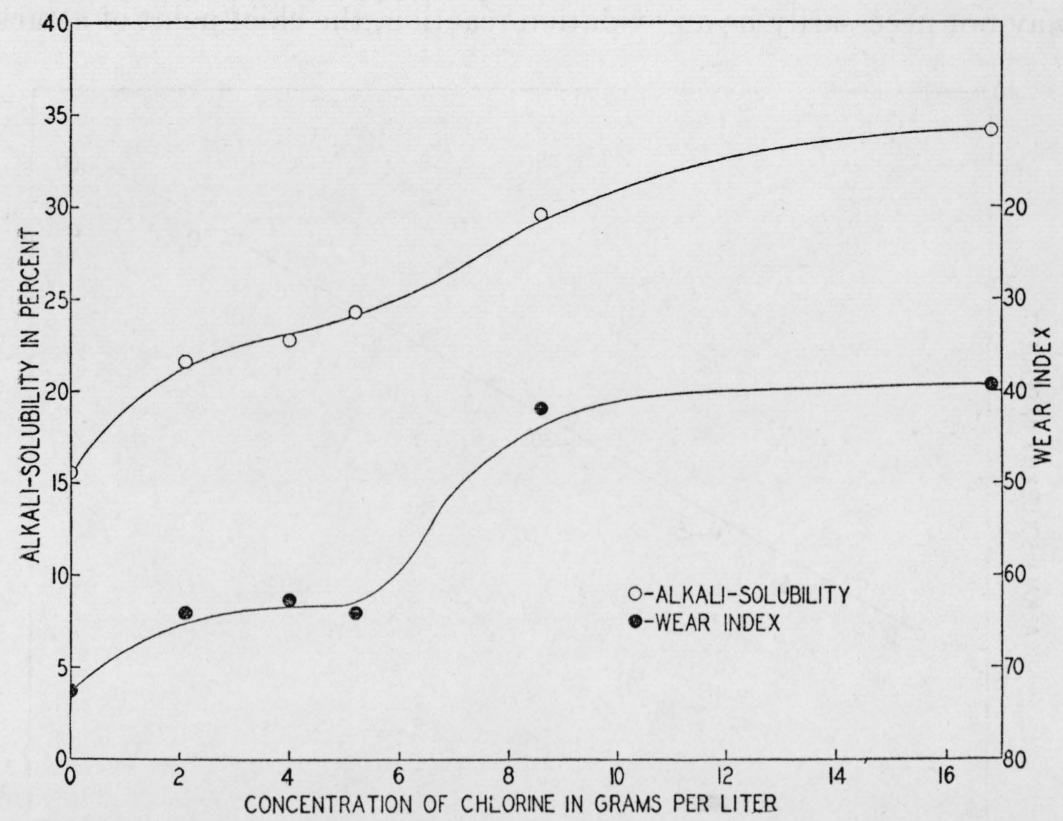

FIGURE 1.-Effect of treating wool with different concentrations of sodium hypochlorite solution at $105^{\circ} \mathrm{F}$ for 1 hour on its alkali-solubility and on the wear index of carpets made from the wool.

TABLE 5.-Effect of different concentrations of sodium hypochlorite solutions at $105^{\circ} \mathrm{F}$ for 1 hour on carpet wool

[The ratio of wool to solution was 1:20, by weight.]

\begin{tabular}{|c|c|c|c|}
\hline $\begin{array}{c}\text { Available } \\
\text { chlorine }\end{array}$ & $\begin{array}{c}\text { Wear } \\
\text { index }\end{array}$ & $\begin{array}{c}\text { Alkali- } \\
\text { solubility }\end{array}$ & $\begin{array}{c}\text { Cystine } \\
\text { content }\end{array}$ \\
\cline { 1 - 2 } g/liter & & $\%$ & $\%$ \\
0 & 72.5 & 15.6 & 9.8 \\
2.1 & 64.1 & 21.6 & 8.9 \\
4.0 & 62.7 & 22.8 & 8.4 \\
5.2 & 64.1 & 24.3 & 8.2 \\
8.6 & 41.9 & 29.6 & 8.0 \\
16.8 & 39.4 & 34.1 & 7.4 \\
\hline
\end{tabular}

1 The wear index of the carpet is the number of thousands of revolutions of the turntable required to wear the pile of a carpet down to one-fourth of its original pile thickness.

\section{EFFECT OF LIGHT ON WOOL}

The results of numerous investigations have shown that the breaking strength, milling properties, affinity for dyestuffs, and sulfur and 
nitrogen contents of wool are altered during the photochemical decomposition of the fiber. However, the determination of any one of these changes does not afford a very sensitive or convenient method for measuring the amount of degradation produced by the action of light. In a recent publication [7] relating to the photochemical decomposition of wool, it was shown that the extent to which wool is degraded during irradiation is directly proportional to the decrease in cystine content and to the increase in alkali-solubility. While subsequent work has indicated that the primary action of light on wool may not necessarily be an oxidation reaction, the chief point of attack

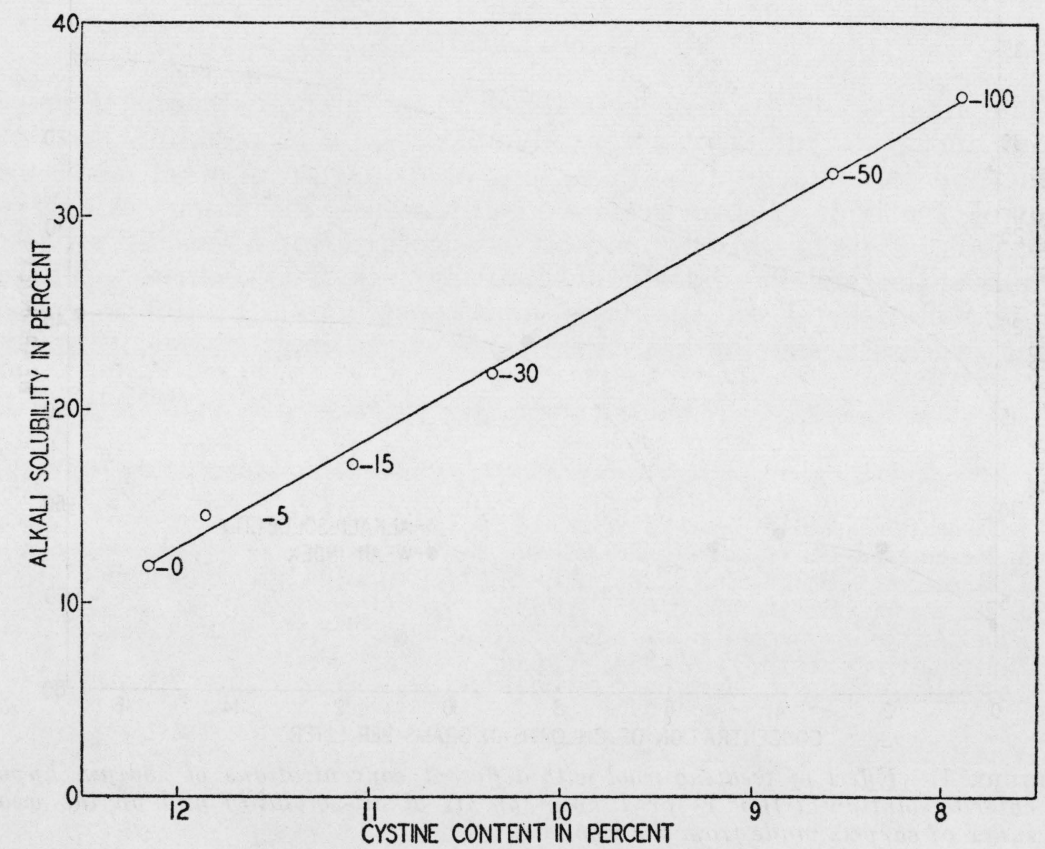

FIGURE 2.-Effect on cystine content and the alkali-solubility of wool of exposure to the radiation of a glass-enclosed carbon arc.

The figures on the curve represent the duration of exposure, in hours.

is still the disulfide group of the cystine in the wool, and the alkalisolubility is correspondingly increased.

Samples of wool top were exposed to the radiation of a glass-enclosed carbon are for different lengths of time from 5 to 100 hours. The effects of the exposures are shown in table 6 . When the data obtained by both methods are plotted against each other as shown in figure 2 , it is readily demonstrated that there is a linear relationship between the increase in the alkali-solubility and the decrease in the cystine content of the exposed samples of wool. 
TABLE 6.-Effect on wool top of exposure to the radiation from a glass-enclosed carbon arc for different lengths of time

\begin{tabular}{|c|c|c|}
\hline Exposure & $\begin{array}{c}\text { Alkali- } \\
\text { solubility }\end{array}$ & $\begin{array}{c}\text { Cystine } \\
\text { content }\end{array}$ \\
\cline { 1 - 1 } \cline { 1 - 1 } $\mathrm{yr}$ & $\%$ & $\%$ \\
0 & 11.9 & 12.2 \\
5 & 14.5 & 11.9 \\
15 & 17.2 & 11.1 \\
30 & 21.9 & 10.4 \\
50 & 32.2 & 8.6 \\
100 & 36.2 & 7.9 \\
\hline
\end{tabular}

\section{CONCLUSIONS}

The alkali-solubility test as outlined in this paper is comparatively rapid and gives sufficiently reproducible results to recommend it as a method for determining the extent of oxidation of wool and as a control method in practical wool processes involving oxidative reactions. The use of the method as a control for a specific process requires the determination of limiting alkali-solubilities. These limits will depend on the type and construction of the material being processed and the use to which it will ultimately be subjected.

\section{REFERENCES}

[Bracketed numbers are citations corresponding to the references in brackets in the text]

[1] J. Research NBS 15, 63 (1935) RP810.

[2] J. Research NBS 16, 301 (1936) RP875.

[3] J. Research NBS 16, 309 (1936) RP876.

[4] J. Research NBS 16, 475 (1936) RP885.

[5] Proc. Am. Soc. Testing Materials [II] 35, (1935).

[6] J. Research NBS 12, 155 (1934) RP640.

[7] J. Research NBS 17, 97 (1936) RP904.

Washington, July 29, 1936. 